\title{
Review on city-level carbon accounting
}

\author{
Guangwu Chen a, b, Yuli Shan c, Yuanchao Hu d, Kangkang Tong e , Thomas Wiedmann ${ }^{\text {b }}$ \\ Anu Ramaswami e, Dabo Guan ${ }^{f, g, h}$, Lei Shi ${ }^{i}$, Yafei Wang a,"*
}

a, School of Statistics, Beijing Normal University, Beijing 100875, China

b, Sustainability Assessment Program (SAP), School of Civil and Environmental Engineering, UNSW Sydney, NSW 2052, Australia

c, Energy and Sustainability Research Institute Groningen, University of Groningen, Groningen 9747 AG, Netherlands

d, Research center for Eco-Environmental Engineering, Dongguan University of Technology, Dongguan 523808, China

e, Humphrey School of Public Affairs, University of Minnesota, Minneapolis, MN, USA

f, Department of Earth System Science, Tsinghua University, Beijing, 100080, China

g, Water Security Research Centre, School of International Development, University of East Anglia, Norwich NR4 7TJ, UK

h, Center for Energy and Environmental Policy Research, Beijing Institute of Technology, Beijing, 100081, China

i, State Key Joint Laboratory of Environment Simulation and Pollution Control, School of Environment, Tsinghua University, Beijing 100084, China

"Corresponding author: ywang@bnu.edu.cn

Abstract: Carbon accounting results for the same city can differ due to differences in protocols, methods and data sources. A critical review of these differences and the connection among them can help to bridge our knowledge between university-based researchers and protocol practitioners in accounting and taking further mitigation actions. The purpose of this study is to provide a review of published research and protocols related to city carbon accounting paying attention to both their science and practical actions. To begin with, the most cited articles in this field are identified and analysed by employing a citation network analysis to illustrate the development of city-level carbon accounting from three perspectives. We also reveal the relationship between research methods and accounting protocols. Furthermore, a timeline of relevant organizations, protocols and projects is provided to demonstrate the applications of city carbon accounting in practice. The citation networks indicate that the field is dominated by pure-geographic production-based and community infrastructure-based accounting, however, emerging models that combine economic system analysis from a consumption-based perspective are leading to new trends in the field. The emissions accounted for by various research 
methods consist essentially of the scope 1-3 as defined in accounting protocols. The latest accounting protocols include consumption-based accounting but most cities still limit their accounting and reporting from a pure-geographic production-based and community infrastructure-based perspective. In concluding, we argue that protocol practitioners require support in conducting carbon accounting so as to explore the potential in mitigation and adaption from a number of perspectives. This should also be a priority for future studies.

2 Keywords: City; Carbon footprint; Carbon emissions; Protocols; Carbon accounting methods 


\section{Introduction}

The Intergovernmental Panel on Climate Change (IPCC) is preparing a special report for cities given their importance in mitigating global climate change.(1) This is a milestone in so far as more cities will be empowered both financially and politically to develop ambitious climate targets and to take actions against global warming, thus advancing the accounting for city-scale carbon emissions.(2) However, unlike the national accounts, cities home to $50 \%$ of world's population but comprise only approximately $3 \%$ of land mass, which means they have to outsource a large number of emissions to outside the city boundary.(3) Thus, the current IPCC framework of national accounts does not match with standard approaches to city-level carbon accounting.

An inventory of any type of emissions is purely territorial. Inventories have been used in different disciplines and used at different scales: urban, regional, and national levels. Examples include the Database for Global Atmospheric Research (EDGAR).(4) These inventories focus on the source of emissions. This is also what the IPCC protocol for nations has focused on. The first time territorial based accounts were referred to as national production-based accounts was in research conducted by Hertwich and Peters (5). One could argue that it should be called territorial accounts and productionbased accounts do not make logical sense for cities, because their geographical scale is much smaller than those of an infrastructure scale. For example, cities use a vast amount of electricity which typically comes from out-of-boundary power stations.

Due to their smaller spatial scale, fundamentally IPCC national source-based accounting does not readily apply to cities. This is why cities have developed protocols that focus on use activities, at least including electricity use that is supplied from outside rather than purely following IPCC's source-based accounting method. Consequently, different types of footprints have emerged from cities. The term 'footprint' is defined in this study as general approaches that link trans-boundary life-cycle emissions with use activities and direct emissions occurring within a city's boundary. Therefore, different accounting perspectives are necessary to address the 'boundary challenge'. These advanced 
perspectives are evolving from territorial source-based accounting to use-activity-based accounting and footprinting, with the latter linking in- and trans-boundary emissions with use activities. The focus on activities provides relevant policies in establishing metrics to track those factors that cities have control over, e.g., housing floor area per capita, housing energy per capita, transportation Vehicle Miles Travelled (VMT) per capita. Pure-geographic production-based accounting can be referred to as a geographic inventory, while the footprints intentionally seek a life-cycle trans-boundary approach. The in-boundary emissions can be referred to as Scope 1, emissions from imported electricity Scope 2 and all other trans-boundary emissions associated with city activities are referred to as Scope 3 . This classification follows the World Resource Institute's (WRI) business protocols (see the official definition of Scope1-3 in Table S1, Supplementary Information (SI)).

The three main methods for city-level carbon accounting related to socio-economic activities are puregeographic production-based (PB), consumption-based (CB), and community infrastructure-based (CIF) methods. The definition of production-based accounting is linked to the System of National Accounts (SNA). $(6,7)$ Production-based emissions broadly refers to the emissions aligning with the boundary of gross domestic product (GDP) accounts,(7) or those related to the local production or economic activities including "Scope 1-3".(8-10) However, the term of production-based emissions is still debatable and requires clear definition (see more details in the section 1, SI). In order to avoid this issue/argument, the pure-geographic production-based accounting method is used hereafter in this study.

Consumption-based accounting measures - the emissions related to consumption activities include territorial emissions plus emissions embodied in imports but deducts the emissions embodied in exports.(11) Consumption-based emissions have been referred to as the 'carbon footprint' (CF).(12) However, given that different definitions of 'footprints' have emerged over the last few years, a more precise term would be consumption-based carbon footprints (CBF).(13)

The community-wide infrastructure-based carbon footprinting method (CIF), estimates carbon emissions direct from and embodied in key infrastructure (e.g. energy, transportation, water, wastewater 
treatment, building materials) and food provisioning to cities.(14-16) Some researchers also refer to it as the hybrid method, because it is a combination of pure-geographic production-based accounting for territorial emissions and Economic Input-Output Lifecycle Assessment (EIO-LCA) or process-based LCA for key transboundary emissions associated with infrastructure and food provision.(13, 16, 17)

Aligning with the IPCC Guidelines for National Greenhouse Gas Inventories, the pure-geographic PB method was adopted for territorial emissions accounts in the first city protocol: International local government GHG emissions analysis protocol $(I E A P) .(18,19)$ This protocol also includes the emissions related to transboundary electricity and adopts the concept of "Scope 1-3" from the Greenhouse Gas Protocol (GHG protocol).(20) The protocols International Standard for Determining Greenhouse Gas Emissions for Cities (ISDGC) and Global Protocol for Community-Scale Greenhouse Gas Emission Inventories $(G P C)$ included the emissions related to key goods and services for city carbon accounting as an optional item, which combined with territorial emissions closely resembles the CIF.(21, 22) The CB method was not completely presented in city accounting protocols until the publication of PAS 2070 in 2013. For the first time, PAS 2070 systematically introduced the CB method within the framework of the environmental extended economic input-output model.(23) The U.S. community protocol also has a separate chapter for the CB method that released in 2013.(24) Although many protocols were developed for city carbon accounting, they show a difference in requirements of accounting, especially for out-of-boundary emissions related to in-boundary activities. This can lead to differing results even for the same city when using different protocols. Thus, the comparison of details of trans-boundary emissions in these protocols is necessary.

Many studies have compared TE, CBF and CIF using pure-geographic PB, CB and CIF as well as standards from different perspectives. Andrade, et al.(25) discussed the city GHG inventory from a production and consumption perspective under the frameworks of GPC and PAS 2070. Kennedy and Sgouridis(26) categorized the activities according to Scope 1-3 by considering the city carbon emissions' relation to the geographical, temporal, activity and lifestyle system boundaries. Hu, et al.(9) explored the relationship of TE, CBF and CIF and conducted a case study for 8 Chinese cities. Lombardi, et al. 
(8) provided a comprehensive review on city-level accounting methods and standards. Chavez and Ramaswami (13) detailed the mathematical relationship among these three methods to categorize cities based on their emission characteristics in the U.S..

However, several issues have not been discussed. For example, an overview of how key literature impacts on the development of city carbon accounting and its related topics is not provided. The links between city accounting protocols and the literature needs to be further explored. The accounting results show a gap in various studies even for the same city (see examples in Ibrahim, et al.(27) and Fry, et al.(28)). This is because of the different understanding of standards, methods and data collection. There is a lack of critical thinking on these differences and the studies that systematically show the connection of TE, CBF and CIF as well as "scope1-3" emissions using the three methods.

In this study, the most cited articles are highlighted using the co-citation networks to exemplify the development of production-based, consumption-based and infrastructure-based methods for city carbon accounting from the academic perspective. The connections between the three perspectives are also described along with the concept of "scope 1-3" in order to address the debate of city carbon accounting, especially for transboundary emissions. Moreover, the calculation of the three methods is provided with detailed models and their advantages and drawbacks as well as applications of each model. Finally, the timeline of organizations, protocols and projects is listed to describe the applications of city carbon accounting in practice, and the descriptions of transboundary emissions in different accounting protocols are presented in a series of figures.

\section{Co-citation analysis for key references and related topics}

Searching the topic concerning city-level carbon accounting we found that 689 articles were published between 1997-2018. The articles were identified using the 'Web of Science' database. A co-citation network was drawn using the software 'CiteSpace' (see Chen(29) for the introduction), which is shown in Figure 1. The top 25 most cited papers corresponding to Figure 1 are listed in Table . The most cited papers appear in the middle of Figure 1 suggesting that the height of their citation potential had been 
reached for the topic of city carbon accounting during 2008-2010. Ten related topics were further summarized by 'CiteSpace' according to keywords. The right hand side of the figure contains a figure key, which includes a. Urban Environmental Sustainability, d Footprint-based Calculation tool, which mainly combine the pure-geographic PB and CIF method, the fields of $b$ City Consumption Based Carbon Footprint, e New Residential Development, g Neighbourhood Level and h Ecological Footprint utilized the CB method. While the others include $c$ Housing type, $f$ Chinese Cities, $i$ Scenario Analysis and $j$ Urban Metabolism usually combine these three methods.

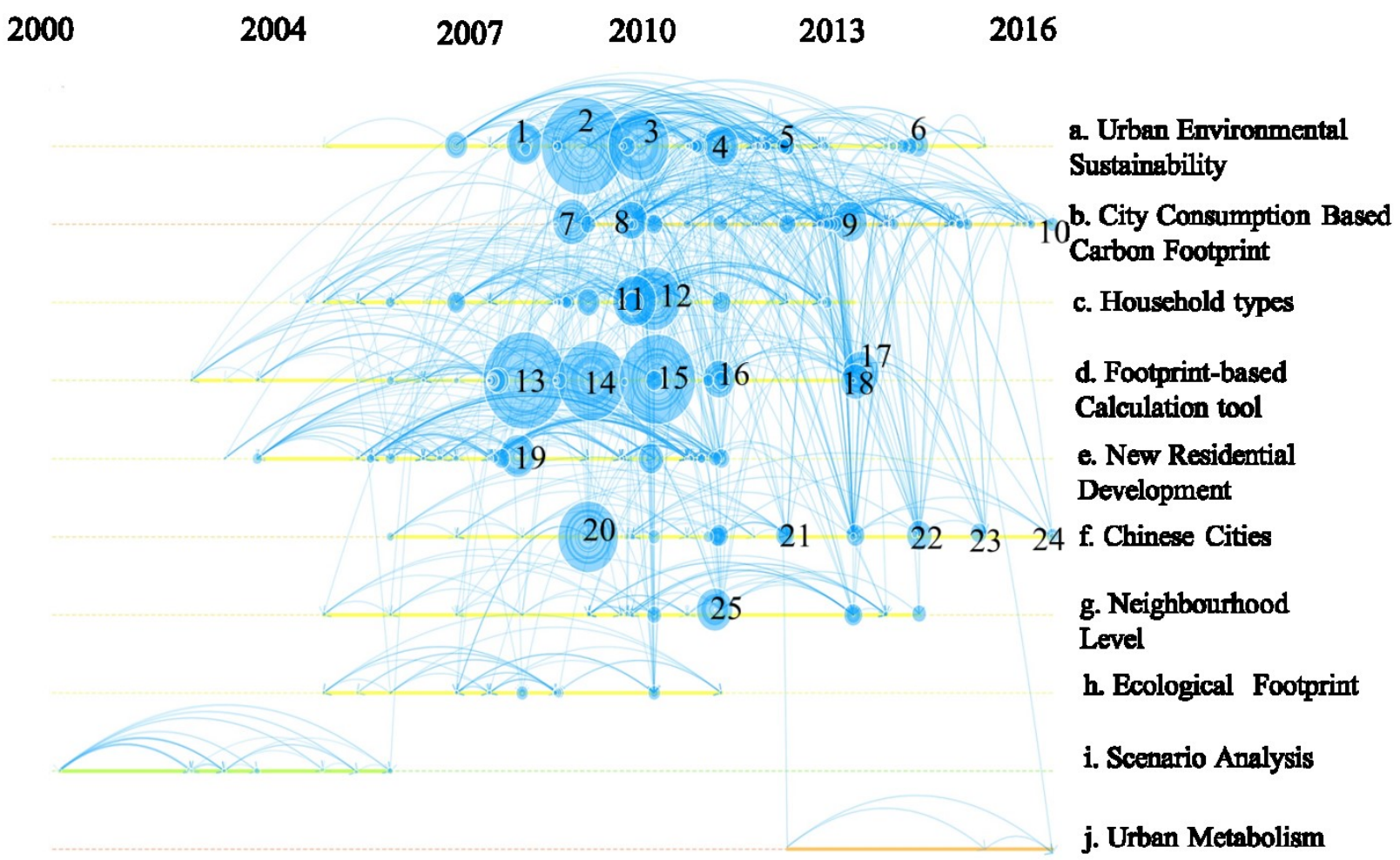

Note: The citations before 2000 and after 2016 are not significant and so these were excluded from the figure. The size of the bubble indicates the number of citations for each paper, while the lines connecting with circles display the co-citation network. The order of the ten topics is arranged by CiteSpace so as to avoid the overlap of the bubbles of each topic. The yellow horizontal lines represent the active period of topic

Figure 1: Co-citation network analysis for city-level carbon accounting based on the 689 articles during 1997-2018.

Table 1: Top 25 most cited papers corresponding to Figure 1 (arranged by topics)

Related References

topics 


\begin{tabular}{ll}
\hline a & 1.Satterthwaite(30); 2.Kennedy, et al.(31); 3.Kennedy, et al.(32); \\
& 4.Hoornweg, et al.(33); 5.Baynes and Wiedmann(34); 6.Jones and \\
& Kammen(35); \\
\hline b & 7.Larsen and Hertwich(36); 8.Lenzen and Peters(37); 9.Minx, et \\
& al.(38); 10.Wiedmann et al.(11); \\
\hline c & 11.Glaeser and Kahn(39); 12.Sovacool and Brown(40); \\
\hline d & 13.Ramaswami, et al.(41); 14. Dodman(42); 15.Hillman and \\
& Ramaswami(14); 16.Ramaswami, et al.(43); 17.Chavez and \\
& Ramaswami(13); 18.Lin, et al.(16); \\
\hline e & 19.Weber and Matthews(44); \\
\hline f & 20.Dhakal(45); 21.Liu, et al.(46); 22.Feng, et al.(47); 23. Lin, et \\
& al.(10); 24.Mi, et al.(48); \\
\hline g & 25.Jones and Kammen(49)
\end{tabular}

Note: The rest of the highly cited references are compiled in section 4.

The pure-geographic PB and CIF methods are the most commonly used methods for city carbon accounting as shown in Figure 1. Satterthwaite(30) discussed the importance of allocation of greenhouse gas (GHG) emissions from production to consumption, especially for electricity (corresponding to Urban Environmental Sustainability in Figure 1). Kennedy et al. (31) combined the carbon accounting and urban environmental sustainability approaches and analysed the differences in emissions of ten global cities; the research was further developed in a later study by Kennedy et al. (32). $\operatorname{Dodman}(42)$ also assessed the patterns of emissions for 26 global cities and presented the results in the form of an inventory. Hoornweg et al. (33) collected the data from various sources and provided GHG baselines for cities and their respective countries. Baynes and Wiedmann(34) wrote a review article concluding that the three approaches for urban environmental sustainability were commonly used in the assessment. Jones and Kammen(35) discussed the effect of population density and suburbanization on city GHG emissions. 
Amongst all the articles, Ramaswami, et al. (41) gained the highest number of citations (corresponding to the Footprint-based Calculation tool). It is the first time that the emissions embodied in transboundary key infrastructure and food supply at city-scale were calculated using the Economic input-output LCA (EIO-LCA) and regional material flow analysis (MFA). (41) The territorial emissions and emissions embodied in transboundary key materials together were defined as CIF in Chavez and Ramaswami(13). The same method was employed for assessing the GHG emissions of eight U.S. Cities (14). Lin et al.(16) evaluated the CIF of Xiamen, China.

Some other topics also employed the pure-geographic PB methods. Dhakal(45) calculated urban energy and $\mathrm{CO}_{2}$ emissions for 35 Chinese cities using the pure-geographic PB method and explored the underlying drivers (corresponding to Chinese cities). Liu, et al.(46) also accounted for the GHG emissions of four Chinese provincial cites using the pure-geographic PB method. Glaeser and Kahn(39) used the pure-geographic PB method to assess the household energy-related emissions from driving, public transit, home heating, and household electricity use in 66 cities of the United States (corresponding to Household types). Sovacool and Brown(40) collected the GHG data through various sources for 12 global metropolises and compared the mitigation policies for these cities (corresponding to Household types).

The CB method is a growing field. The research on it, especially for City Consumption Based Carbon Footprint, has witnessed a trend of continued growth during 2013-2016 (in Figure 1). Larsen and Hertwich(36) assessed the CBF of the city of Trondheim, Norway using the hybrid LCA by nesting the matrix of process-based emissions in the input-output table. Lenzen and Peters(37) evaluated the CBF of Sydney and Melbourne, Australia using a MRIO model and tracked the embodied emissions to cities' hinterlands. Minx et al.(38) assessed the CBF of cities in the UK by combining the national scale MRIO with disaggregated final demands based on the MOSAIC household survey.

Some other topics are also related to the CB method. Weber and Matthews(44) combined the multiregional input-output (MRIO) model with the household expenditure survey data for assessing the 
household CBF in the U.S. (corresponding to New Residential Development). Jones and Kammen(49) calculated the household carbon footprint of 28 cities using the EIO-LCA model with household expenditure survey (corresponding to Neighbourhood Level). This neighbourhood-specific carbon footprint accounting and mapping were further conducted for 700 California Cities, and the abatement potential was discussed with the development of a set of tools named CoolClimate ${ }^{l}$. (50) Feng, et al.(47) accounted for the CBF of four provincial cities of China with a provincial-scale MRIO model (corresponding to Chinese cities). Lin, et al.(10) compared the CIF and CBF based on the case of the city of Xiamen, China (also corresponding to Chinese cities).

Two emerging fields of the secondary classification in 2016, as shown in Figure 1, are City Consumption Based Carbon Footprint and Chinese Cities. The two most cited papers corresponding to these two fields are Wiedmann, et al.(11) and Mi, et al.(48). Wiedmann, et al.(11) made the first attempt at accounting for urban consumption-based emissions using a close city-scale multiregional inputoutput model with a planetary boundary. This work also harmonized the concept of scope 1-3 emissions with consumption-based accounting. Mi, et al.(48) not only accounted for the carbon footprint of 13 Chinese cities, but more importantly, contributed to the database titled China Emissions Accounts and Datasets. The data of the city-level emissions was offered free for download (also see other fundamental works contributed by Shan, et al.(51), and the $\mathrm{CO}_{2}$ emissions for 182 Chinese cities in Shan, et al.(52).

Two highly cited papers during 2017-2018 are Chen, et al.(53) and Su, et al.(54), which are not shown in Figure 1 due to the relatively small number of citations they have received so far (which of course is not unusual given how recent each article is). These two papers both employed the input-output model that belongs to the CB method. They developed 'industrial linkage' and 'structural decomposition' analysis separately. The two papers share a similarity in combining embodied emissions with an analysis of the urban economic structure.

\footnotetext{
${ }^{1}$ http://coolclimate.org/
} 
276 Some topics show a weak connection with other topics. For example, the topic scenario analysis appears as early as the year 2000 , however, it was not often cited by carbon accounting methods. While some of the literature included the three methods as a part of the research for urban metabolism, they only contribute to the socio-economic processes, omitting natural process.(55) The citation networks show a weak connection between the topic of urban metabolism and others which indicates that the contribution of three methods to this topic is limited. However, when conducting CIF or TE, energy or material flow analysis is a basic process. These concepts actually have a strong linkage with urban metabolism, while some papers may not specify the term.

\section{Debate and relationship of TE, CIF, CBF and Scope 1-3}

The area of most attention and debate on the topic of city carbon accounting is on transboundary emissions, which are calculated by the consumption-based method and infrastructure-based method. Under the community-wide infrastructure-based carbon accounting method, the emissions related to key infrastructure are regarded as the essential part of transboundary emissions, while the other parts of transboundary emissions, e.g. embodied in other non-infrastructure services and provision of goods, are not the priority because of data availability.(41) This idea is also presented in different standards in terms of various requirements for the calculation of scope 3.(22-24) In contrast, the consumption-based method claims such as transboundary emissions related to economic activities, including many nonphysical flows like services, which can be calculated through the emissions embodied in trade.(11)

In order to connect the different accounting methods, Figure $\mathbf{2}$ is drawn with TE, CIF, CBF and the complete "Scope 1-3" corresponding to their respective methods. The city carbon footprint (CBF) is a consumption-based measure that adds emissions embodied in imports (EEI) to industry-related territorial emissions (also called scope 1 emissions, see WRI, C40 and ICLEI(22)). It also includes subtracted emissions embodied in exports (EEE). EEE are the territorial emissions that are exported (or the local production emissions that serve exports) and can also be accounted for under the input-output framework but excluded from CBF. Territorial emissions (TE) using the pure-geographic production- 
based accounting method constitute a key part of CBF. To some extent, the quality of the territorial emissions decides the quality of CBF, since the consumption-based method does not account for emissions, but allocates the territorial emissions in each of the supplying regions to final consumers through monetary flows.(56) The rest of the territorial emissions (RTE) are noted as local production emissions that serve local final demand. In contrast, the CIF measures responsibility including TE and emissions related to key imported materials.(13) CIF does not exclude the EEE.(9, 10, 13) Notably, household direct emissions (such as household natural gas and transport fuels) are independent of the city production system and are thus calculated individually and added to the results of the city carbon accounting method.

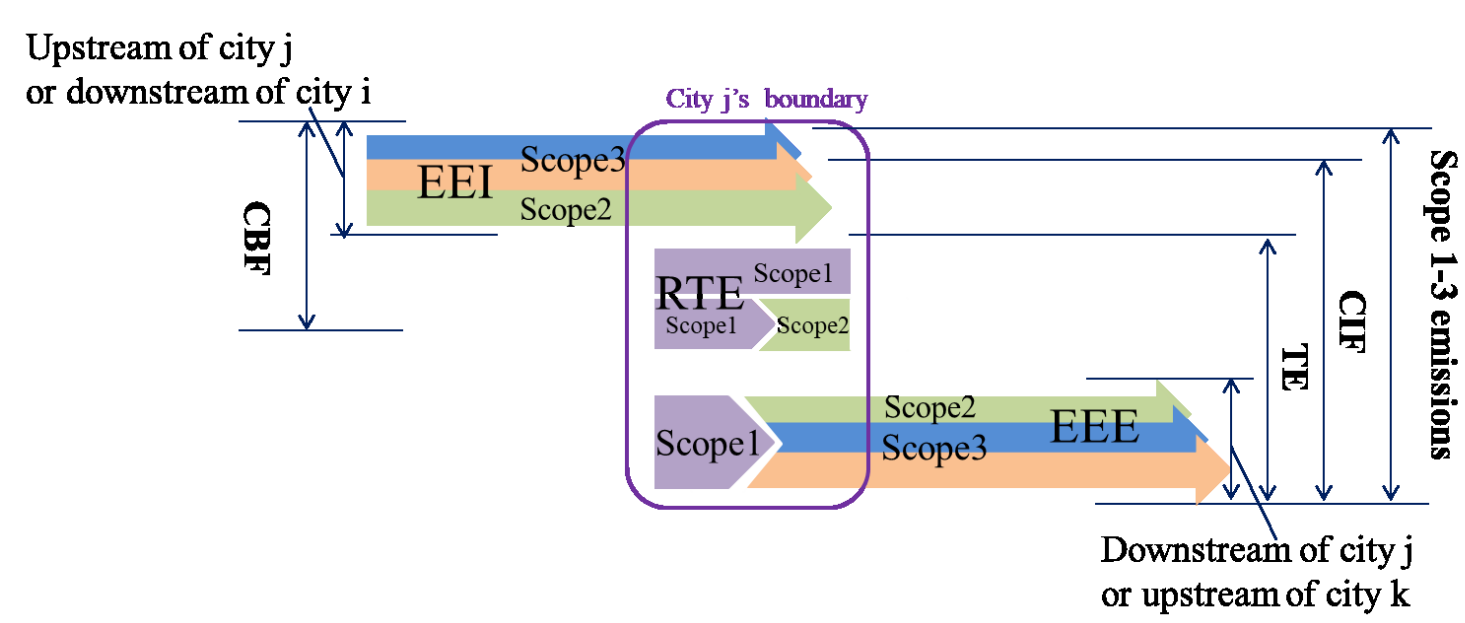

Scope3 Emissions related to key materials: water, waste, energy, transport, food and constuction
Scope3 Emissions related to other goods and services

Note: $\mathrm{CBF}=$ Consumption-based Carbon footprint $(\mathrm{CB}$ method $) ; \mathrm{CIF}=$ Community-wide infrastructure footprint (CIF method); TE = Territorial emissions (Pure-geographic PB method); Scope 1-3 emissions = complete scope 1-3 emissions defined in city protocols; $\mathrm{EEI}=$ Emissions embodied in imports; $\mathrm{EEE}=$ Emissions embodied in exports; RTE $=$ Rest of territorial emissions.

\section{Figure 2 the relationship analysis for TE, CIF and CBF}

In Figure 2, the complete scope 3 includes the emissions related to key materials as well as other goods and services. CIF calculates only the emissions related to key infrastructure and food provisioning. The same requirements are presented in the protocols while the other goods and services are not detailed or 
mentioned (see details in section 4). In contrast, the consumption-based method calculates the complete scope 3 associated with final consumption regardless of key materials or none-key materials.

The downstream and upstream emissions from a city perspective can also harmonize with the concept of "Scope 1-3" which should be distinguished from the corporate perspective (see Error! Reference source not found. in SI). In Figure 2, when city j's downstream emissions become city k's upstream emissions, the scope 1 of city j will also become the scope 2 and 3 of city $\mathrm{k}$. These emissions are related to the products and services which are exported from the city $\mathrm{j}$ to city $\mathrm{k}$. In the RTE part, the production of electricity within the boundary could lead to the conversion of scope 1 to scope 2 and the calculation should avoid the double counting.

Figure 2 was drawn only for displaying the emissions as a final result of calculation, and the processes of carbon allocation from production to consumpiton are complicated and are ignored in this figure. For example, a part of imported products is involved in local production processes as intermediate products. Thus EEI related to these intermediate products will mix with RTE and be reallocated to final consumptions. In contrast, the rest of the imported products are final products which are directly consumed by city dwellers, and this part of EEI does not mix with local production processes. This information is shown in Wiedmann, et al.(11), which is not reported here.

The focus of CIF and "Scope 1-3" is on a single city while TE and CBF have the advantage of being able to explore the total emissions of a group of cities. The sum of multi-cities' CIF or "Scope 1-3" needs to deduct the overlap part since one city's imports could be another city's exports unless cities have no trade between them (page 14, (23)). The scope 2 also needs to avoid double counting within the boundary since emissions generated from electricity production could overlap with upstream and downstream.(22) In contrast, multiple cities' CBFs or TEs can be added up without deductions. CBF was designed to exclude EEE, thus providing an advantage in studying the network of CBF for multiple cities. TE does not include the EEI, hence the multi-cities' TEs can be added together. 
Many other accounting perspectives that designed to advance a more detailed understanding of urban carbon emissions are connected with Scope 1-3 and integrated within the same framework (see Figure S1 and details in SI).

In sum, CBF, TE, and CIF have provided three perspectives to explore the relationship between urban activities and carbon emissions. CBF demonstrates the direct and indirect carbon impacts associated with consumption activities in cities. It delineates the carbon impact of different consumption patterns in cities to inform consumers' choices and develop consumption-oriented management tools.(49) TE estimates carbon emissions from in-boundary activities informing the direct carbon impact of various local activities. TE adopts the method proposed by IPCC for national accounting, detailing the impact of anthropogenic activities within a city's boundary. This method is an easy and direct channel to link with national carbon accounting to demonstrate the added up full scope of the anthropogenic carbon impact of cities or urban areas. Additionally, it provides data for co-benefit analysis of local mitigation actions. CIF investigates direct and indirect carbon impacts from infrastructure provisioning to city dwellers as both consumers and producers. CIF also provides the benchmark of infrastructure use by key users to inform urban planning for low-carbon city development. $(14,41)$ The transboundary carbon impacts associated with infrastructure provisioning demonstrates at what sectors and what scale the multi-regional collaboration is needed for mitigation strategies.(57)

\section{The calculation of TE, CIF and CBF}

Pure-geographic Production-based GHG accounting,(43) or Purely Geographic Accounting (10) also refer to the IPCC territorial emission accounting system.(51) Within the framework of pure-geographic $\mathrm{PB}$, territorial emissions (TE) are calculated by multiplying the data of activities with emission factors (EF). These are classified into five categories including: (1) Energy, (2) Agriculture, (3) Forestry and other land uses (AFOLU), (4) Industrial Process or Industrial Processes and Product Use (IPPU) and (5) Waste and Others. According to the IPCC guidelines this is an accepted framework for the national GHG emissions accounting.(19) There are three tiers of calculation representing the three levels of 
complexity and accuracy that are provided in the IPCC guidelines. The guidelines do not account for the imported electricity for nations.(19) When calculating the emissions of imported electricity for cities, the EF needs to be extracted from local power stations, or use the national or grid average data. The selected applications for this method are shown in Table, while the calculation of TE is given in Eq.1.

$$
T E=A D \cdot E F
$$

\section{Equation 1}

Where $\boldsymbol{T E}$ means territorial emissions, $\boldsymbol{A D}$ equals the data of activities including industrial processes and energy consumption. $\boldsymbol{E F}$ is the emission factors corresponding to certain activities. Notably, when referring to energy consumption, $\boldsymbol{E F}$ consists of the net caloric value of fossil fuel, $\mathrm{CO}_{2}$ emissions per net caloric value produced of fossil fuel and the oxidation ratio of fossil fuels.(51)

The pure-geographic PB method using survey data of industrial activities also enables the accounting at the prefecture-level and even the 1-km grid level.(58) For example, the survey data of 1.58 million industrial enterprises, including fuel consumption details at the facility level, allows detail to be provided down to the $10 \mathrm{~km}$ gridded $\mathrm{CO}_{2}$ emission map of China.(59) This bottom-up method with detailed survey data at the enterprise-level is more accurate than the nationally downscaled method using socioeconomic proxies (see the comparison in Wang and Cai(60)). However, the enterprise-level survey needs to deal with the mismatch of the location of emissions i.e. the emissions are allocated to the headquarters of enterprises, rather than the location where they actually emit (see page 181, Cai(61)). Several databases using the spatial solution are discussed in Table S2, SI.

CBF is calculated by the CB method which does not account for the emissions, but allocates the TE from production to consumption through the classic Leontief pull model.(56) CBF is also called consumption-based carbon footprint $(\mathrm{CBF})$ in order to distinguish more clearly from the CIF.(9, 10, 13) However, from the national perspective, $\mathrm{CBF}$ is consistent with the use of the definition of the term 'carbon footprint' in the literature and in practice, i.e. a carbon footprint is by definition always consumption-based (and also referred to as just "CF").(12) By adopting the same principles, the same concept can be transferred in a consistent way to the city level.(11) Therefore, CF or CBF could be 
chosen depending on the topics under analysis, and they mean the same thing. The calculation of CBF is given in Eq.2

$$
C B F=f \cdot L \cdot y+h h
$$

\section{Equation 1}

Where $\boldsymbol{C F}$ is carbon footprint, $\boldsymbol{f}$ is direct industry emission intensities $\boldsymbol{L}$ is Leontief Inverse, and y is household final demand. $\boldsymbol{h} \boldsymbol{h}$ is the household direct emissions.

The Leontief pull model relies on input-output tables which can be categorized into Single-Regional Input-output tables (SRIO) and Multi-Regional Input-output tables (MRIO) (see examples in Table ). In SRIO, the domestic and international import columns are highly aggregated. The imported products cannot be traced back to their origins. The premise of calculating the emissions embodied in imports is to assume the carbon intensity (i.e. $\boldsymbol{f} \cdot \boldsymbol{L}$ in Eq. (2)) of imported goods and services equals the local carbon intensity. This will yield an error since the production efficiency of different regions varies a lot. To overcome this problem, a single regional model can also be expanded to a multi-scale single regional model with detailed carbon intensity applying to domestic and international trade to the region.(62)

In contrast, the imports and exports are divided into regions in MRIO, thus it is possible to apply the different carbon intensities and production technology for imported products according to their origins. MRIO not only enhances the accuracy but also enables the network of embodied emissions through imports and exports to be counted. Several MRIO models also embed the emissions embodied in international imports by combining the carbon intensity with trade for countries or global regions.(10)

This MRIO model can be further improved by nesting the 'rest of world' region into the MRIO table rather than only using the carbon intensity for imported products. By doing so, the MRIO model forms a closed model connecting the world's economies, which is referred to as the Global Multi-Regional Input-output table (GMRIO).(9,63) The advancement of the GMRIO is to enable a planetary boundary and to allow the assessment of emissions embodied in trade of subnational regions and even cities across 
countries.(64) From SRIO to GMRIO, the footprint assessment boundary plays a crucial role and the arising truncation error could be significant.(28)

For many cities in the world, it is rare to obtain the city-scale input-output table. When calculating CBF, some studies use the national carbon intensity derived from the national input-output model, which is termed an EIO-LCA.(65) This model can only be used for estimating household CBF because the business capital expenditure and government consumption parts are missing when there is no city-scale input-output table or survey data. The business capital expenditure and government consumption can make up $30 \%$ of a city's total CBF ((66), also see the same percentage for U.K.(67)). Thus, one important indicator to distinguish the MRIO from EIO-LCA is whether a city-scale input-output table has been developed. The use of national or subnational carbon intensity for local carbon footprint accounting leads to an issue of uncertainty. The accuracy depends on how close the local production system is to the national or subnational one, because local carbon intensities usually show a wide range of difference. For example, carbon intensity between cities within a nation can range from 0.09 to 7.86 $\mathrm{kgCO}_{2}$ per $\$$ GDP.(68) The uncertainty is also generated when matching up the sectors of input-output tables with products. Sectors are highly aggregated in the input-output table, while products vary a lot with different brands representing different production processes and carbon intensities in practice. Heinonen and Junnila(69) constructed a hybrid LCA by substituting output matrices of the EIO-LCA model with process data, thus increasing the accuracy of the model compared to direct input-output analysis and decreasing the inherent truncation error of process LCA.

Under the consumption-based accounting category, controlled carbon footprint answers the question of how much embodied emissions are actually controlled by the region. $(70,71)$ This is important when cities attempt to make an effective policy targeting the emissions embodied in consumption for mitigation, because without a precise focus on the controlled carbon footprint, entities can easily transfer or outsource their emissions through other supply chains that have not paid attention to these factors, leading to an ineffective mitigation effort. Similar to the economic system, tracking the "internal control in an ecosystem and the extent or degree to which elements influence each other and contribute 
to the system's overall flow-storage pattern" is an important topic for the ecological network analysis, and the network-based concept 'control' can be captured by identifying and quantifying the pair-wise system interactions. (72) Combining the principals of Network Control Analysis with Input-Output Analysis (i.e. IOA-NCA hybrid method) is based on the assumption that the human socio-economic system is similar to an ecological system with elements connected to each other in the network through these input-output environments,(73) thus applying the common rules in both economic and ecological systems. Studies using IOA-NCA hybrid method have been conducted for urban virtual carbon flow analysis by applying the ecological principals in an environmental extended economic input-output system (see Table 2).

CIF also refers to Geographic-Plus infrastructure Supply Chain GHG Footprints (43) or TransBoundary Infrastructure Supply Chain Footprints (15). It is calculated by the method of combining the pure-geographic PB for scope 1 and scope $2(\boldsymbol{S} 2)$ with the process-based LCA or EIO-LCA for transboundary emissions related to key infrastructure and food provision in scope 3 (KS3). Processbased LCA is accurate, transparent and suitable for microsystems, but it is labour-intensive and subject to the "truncation error". While using the MFA with EIO-LCA the physical units of products have to be converted into monetary units for matching up with the carbon intensity generated in the EIO-LCA model. This will inevitably generate a converting error. The function is given in Eq.3.

$$
C I F=T E+S 2+K S 3
$$

Equation 3

Where $\boldsymbol{C I F}$ is community-wide infrastructure footprint, $\boldsymbol{S} \mathbf{2}$ represent scope 2 emissions while $\boldsymbol{K S} \mathbf{3}$ equals transboundary emissions related to key infrastructure use provision. The mathematical relationship between PB, CIF, and CBF has been detailed in Chavez and Ramaswami(13).

In theory, a city should report the direct and complete supply chain emissions, but collection of the data of process-based LCA and material flows is labour-intensive. It is hard to cover the whole global supply chain for a product. Also it is not realistic to capture information of all products for cities. Sometimes, the data of process-based LCA has to be obtained through various sources such as databases, colleagues' 
500

501

502

503

504

505

506

507

508

509

510

511

512

513

514

515

516

517

518

519

520

521

522

523

524

525

526

research or companies' reports, rendering the consistency, transparency and boundary uncertain. In practice, calculating the emissions embodied in transboundary key materials by EIO-LCA or processbased LCA is a compromise regarding data availability.

Some calculations are not listed in Table because of a different combination of methods and results. To illustrate, Froemelt, et al.(74) employed process-based LCA for emissions embodied in both key imported and exported goods, but constructed the consumption-based and territorial emissions rather than CIF. Hu, et al. (9) selected the transboundary emissions embodied in key materials calculated by GMRIO and compared CIF with CBF and TE. Some other methods including the physical input-output model, mixed-unit input-output model and mixed-unit hybrid LCA are available in other applications but not at city-level due to the data availability (see applications in Teh, et al.(75)).

The other estimation methods associated with spatial resolution are not included in Table since they are not recorded in city carbon accounting protocols. These methods downscale the carbon emissions from a nation-scale or subnational scale to finer scales using spatial proxies and present results in gridded maps. The premise for conducting these methods is to assume that spatial proxies correlate with carbon emissions. For example, night-time light imagery is widely used as a proxy for estimating urban direct emissions ((76), see other city-level examples in Su, et al.(77), Wang and Liu(78) and Liu, et al.(79)). Daniel, et al.(80) downscaled the CBF from a nation-scale or subnational scale to city-scale for 13000 cities using population density and income as proxies. Global emission inventories in the Emission EDGAR combined several proxies ranging from population density to specific point source location maps for estimating emissions of different economic sectors.(4) The application of EDGAR at city-level is provided in Marcotullio, et al.(81). Several other well-known databases relying on downscaling techniques are also available at the spatial scales including the Carbon Dioxide Information Analysis Centre (CDIAC), Fossil Fuel Data Assimilation System (FFDAS), and the Open Source Data Inventory of Anthropogenic CO2 Emission (ODIAC).(82) In sum, all these methods and databases are advantageous at estimating a large scale of city-level carbon emissions and are considered 
to be complements for the three main methods when cities have sufficient bottom-up data of socioeconomic activities.

Table 2 the selected examples corresponding to respective models

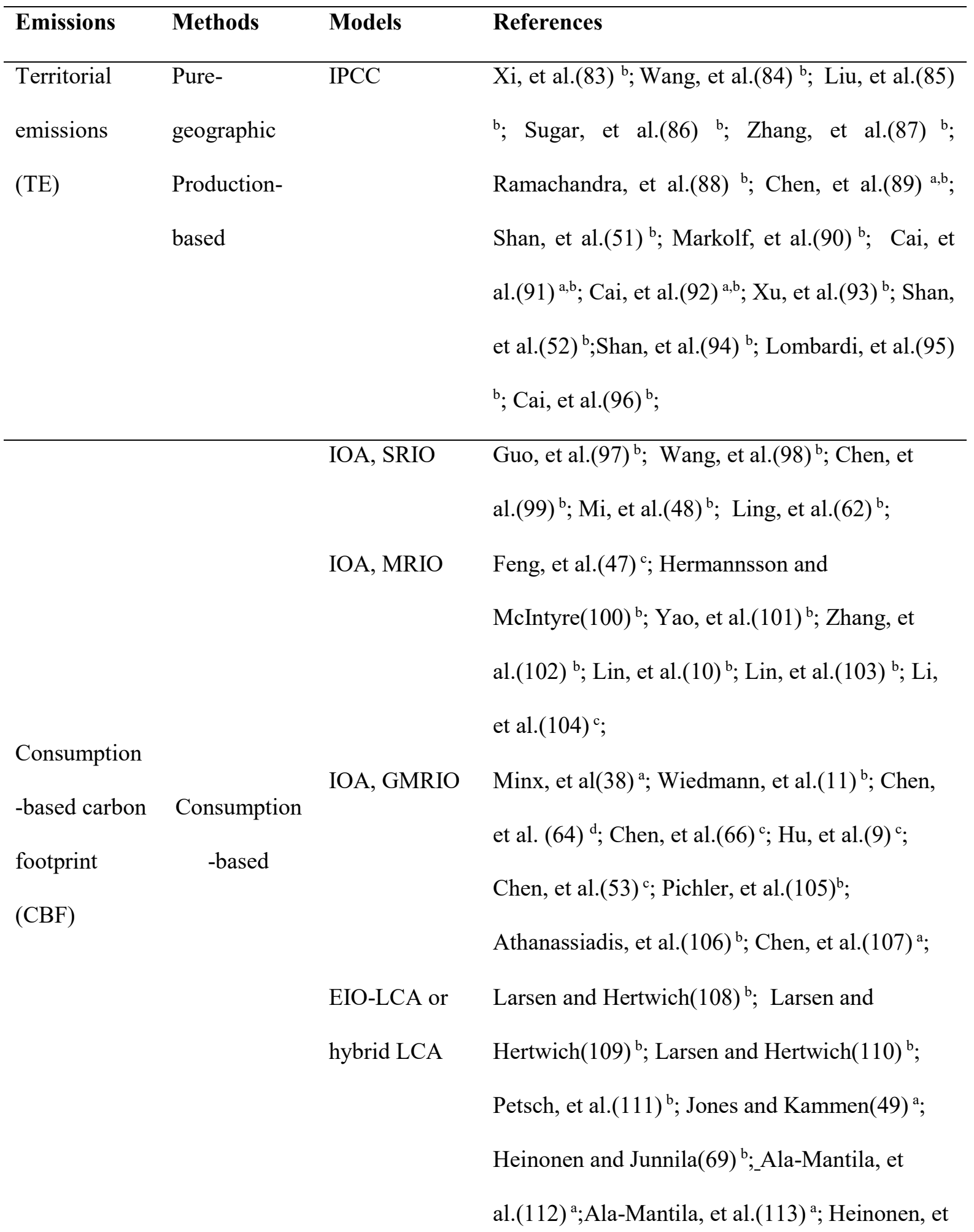


al (65) ${ }^{\mathrm{b}}$; . Jones and Kammen(35) ${ }^{\text {a.; }}$ Dias, et

al.(114) ${ }^{b}$;

IOA-NCA Chen and Chen(70) ${ }^{\mathrm{b}}$; Chen and Zhu(71) ${ }^{\mathrm{b}}$; Chen

hybrid method and Chen(115); Chen et al.(116) ${ }^{\text {b }}$; Chen et

(Controlled al.(117) ${ }^{\mathrm{b}}$;

Carbon

footprint and

others)

\begin{tabular}{|c|c|c|c|}
\hline Community- & CIF method & Community & Chavez and Ramaswami(118) ${ }^{\text {b}}$; Chavez and \\
\hline wide & (IPCC for TE & Wide with & Ramaswami(13) ${ }^{\text {b; }}$ Hillman and Ramaswami(14) \\
\hline infrastructure & plus process- & Scope $1+2$ & b; Chavez, et al.(15) ${ }^{\text {b; }}$ Lin, et al.(16) ${ }^{\mathrm{b}}$; Tong, et \\
\hline footprint & based & and Scope 3 & al.(119) $)^{\mathrm{b}}$;Qi, et al.(17) ${ }^{\mathrm{b}}$; Kennedy et al. (31) ${ }^{\mathrm{b}}$; \\
\hline \multirow[t]{4}{*}{ (CIF) } & LCA/EIO- & related to & \\
\hline & LCA for & seven key & \\
\hline & transboundar & infrastructure & \\
\hline & y emissions) & & \\
\hline
\end{tabular}

Note: This table gained its impetus from Lombardi, et al.(8) and Wiedmann,et al.(11). It is reorganized and complemented according to our understanding of the authors key concepts. Scales: a, prefecture/suburb/households; b, single city or multiple cities; c, inter-city within a country; $\mathrm{d}$, transnational inter-city.

\section{Organizations, protocols and projects}

While the leading edge of research on carbon accounting has been pursued by university-based researchers, many of the initiatives on city climate change as well as their protocols and projects have been influenced by practitioners. Many cities are members of these organizations such as C40, ICLEI and Compact of Mayors, and report their emissions according to protocols through their online platforms. The timeline of the development of organizations, protocols and projects are given in Note: GPC and US-ICLEI Community Protocol both are trying to coordinate and came out the same time. US Community Protocol came out in 2012 and the latest version was published in 2013.

\section{Figure .}

ICLEI was founded in 1990 with more than 200 local governments worldwide who were seeking to achieve tangible improvements in global sustainability through local actions.(120) ICLEI began its 
550 Urban $\mathrm{CO}_{2}$ Reduction Project early in 1991, and the Cities for Climate Protection Campaign in 551 1993.(121) The campaign provided an opportunity for the accounting and collecting of city-level GHG 552 emissions, thus contributing to the development of city-level carbon accounting protocols.

553

554 C40 was founded in 2006 originally with 40 'megacities' address climate change. It now connects more 555 than 90 of the world's most populated cities, representing over 650 million people and one-quarter of 556 the global economy.(122) Both ICLEI and C40 collaborate with the carbon disclosure project (CDP) 557 and release city self-reported GHG emissions on CDP's platform (most are based on the GPC and 558 account for scope 1 and 2). The Covenant of Mayors is the most ambitious initiative in the fight against 559 global warming in the European Union (EU) and is supported by EU institutions.(123)

560

561 The Compact of Mayors was launched at the climate summit in 2014 with support from UN-Habitat, it consists of C40, ICLEI and United Cities and Local Governments (UCLG). The Compact of Mayors has become the largest international alliance of cities and local governments for climate change actions

564 after merging with the Covenant of Mayors in 2017.(124) 


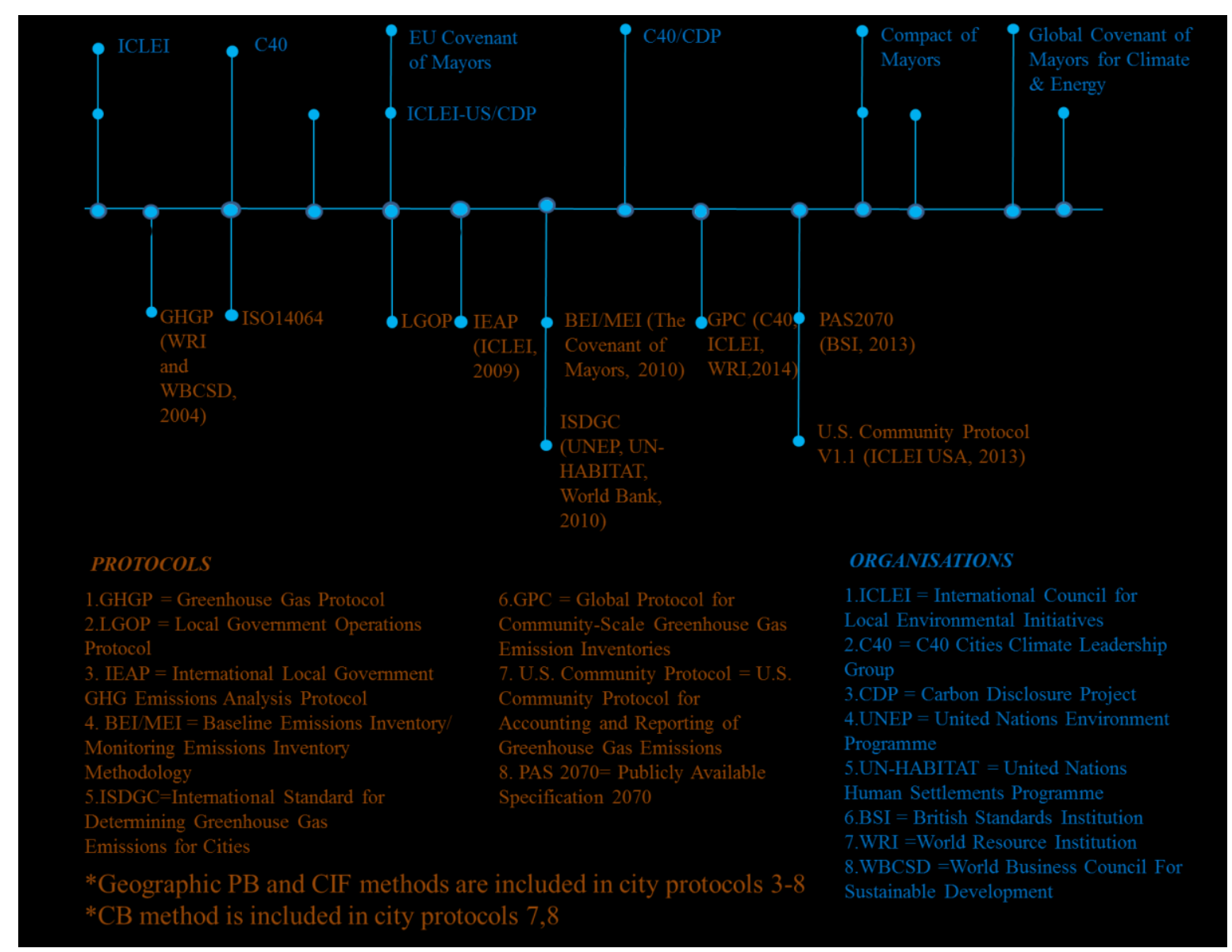

Note: GPC and US-ICLEI Community Protocol both are trying to coordinate and came out the same time. US Community Protocol came out in 2012 and the latest version was published in 2013.

Figure 3 timeline of organizations, protocols and projects for city climate change

IPCC assessment reports (AR) 1-3 during 1990- 2001 drew global attention to addressing the global

warming issue. The IPCC AR5 even has separate chapters for cities while a special report will be provided in AR7.(1)

577 WBCSD and WRI(20) developed a GHG protocol for corporates such as companies, universities and local governments. The concept of "scope 1-3" emissions was systematically presented for corporates.

579 This concept was adopted by city protocols and the comparison of scope1-3 for corporates is presented in Table S1 of SI. In 2004, ISO 14064 also provided the framework for quantification and reporting of greenhouse gas emissions at the organization level. In 2009, ICLEI developed the first city carbon accounting protocol (IEAP) after the publication of Protocol for Local Government $(L G O P) .(18,125)$ 
The standards of $B E I / M E I$ and $I S D G C$ were published in 2014. BEI/MEI only requires mandatory quantification of energy-related $\mathrm{CO}_{2}$ and it is the protocol developed by the Covenant of Mayors for European cities.(126) In 2013, ICLEI developed the U.S community protocol for cities in that country whose protocols include "sources" and "activities" rather than the scopes framework and different emission categories that are contained in the IPCC Guidelines.(127) PAS 2070 is the first protocol to systematically introduce the Environmental Input-output model and provide the consumption-based inventory.(23) GPC is the product of C40, ICLEI and WRI and the most popular protocol used by global cities.(22)

In-boundary emissions' accounting is clear in city protocols and closely aligned with the IPCC guidelines (except the U.S community protocols). However, the transboundary emissions are not required in IPCC guidelines for national level, thus different requirements for accounting transboundary emissions are shown in city protocols (see Figure ). All the protocols agree with the inclusion of emissions related to imported electricity. While the emissions related to waste, aviation and water transport became the mandatory option in the latest protocols, the emissions embodied in food, water, construction material and energy are still optional or partly included in ISDGC, U.S Community Protocol and GPC.(21, 22, 24) The uncertainty of data collection, calculation and methodology is the main concern for these protocols. In contrast, PAS 2070 systematically includes the community-wide CIF and the CB method for calculating emissions embodied in products and services along the supply chain.(23) However, none of the protocols provides the detail of emissions embodied in other goods and services which has a higher requirement for data collection.

All city accounting protocols include the pure-geographic PB and CIF method. The CIF method is close to the definition of Direct Plus Supply Chain (DPSC) in the British protocol PAS 2070. The U.S. Community Protocol and GPC have no specific name for CIF, but the accounting approaches are similar and results are recommended to be presented in the form of an inventory. $(22,24)$ In contrast, only U.S. Community Protocol and PAS 2070 have a separate chapter for the CB method.(23, 24) These two 
protocols realize that different accounting approaches take into account different responsibilities, thus

612 the choice is not either/or, but rather both/multiple perspectives. Scope 1-3 emissions can also be

613 calculated by both hybrid and CB methods and reported in an inventory.(11, 128)

614

615 Different accounting methods not only reflect the understanding of urban activities' impact from different perspectives, but also provide information to support different policies either to cities, to regional governance bodies or higher-level government. Currently, many of these protocols and discussions have focused on how to construct the inventory, while not clearly outlining how the information can be linked with policies. Each approach naturally has advantages and disadvantages associated with them, cities should not choose the "best" method, rather they should choose the most useful method to support their mitigation strategies based on their particular context.

622

623

\begin{tabular}{|c|c|c|c|c|c|c|}
\hline \multirow[t]{2}{*}{ Protocol name } & \multicolumn{3}{|c|}{ Community-wide perspective ( in- and trans-boundary) } & \multicolumn{2}{|c|}{$\begin{array}{l}\text { Consumption based-perspective (in- + trans- } \\
\text { boundary) }\end{array}$} & \multirow{2}{*}{$\begin{array}{l}\text { Pure-geographic } \\
\text { production-perspective } \\
\text { (in-boundary) } \\
\text { Purely-territorial } \\
\text { emissions cover IPCC } \\
\text { sectors }\end{array}$} \\
\hline & $\begin{array}{l}\text { Community- } \\
\text { wide direct } \\
\text { (Purely- } \\
\text { territorial source } \\
\text { based } \\
\text { accounting) } \\
\text { covers IPCC } \\
\text { sectors }\end{array}$ & $\begin{array}{l}\text { Community- } \\
\text { wide direct + } \\
\text { net imported } \\
\text { electricity }\end{array}$ & $\begin{array}{l}\text { Community-wide direct + } \\
\text { imported electricity + trans- } \\
\text { boundary life-cycle for key } \\
\text { infrastructure and food supply } \\
\text { sectors (energy, transport, } \\
\text { construction materials, water, } \\
\text { wastewater/waste and food) }\end{array}$ & $\begin{array}{l}\text { Household } \\
\text { consumption only } \\
\text { (from household } \\
\text { expenditure survey) }\end{array}$ & $\begin{array}{l}\text { Household } \\
\text { expenditure, } \\
\text { government } \\
\text { expenditure, and } \\
\text { business capital only } \\
\text { from input-output } \\
\text { table }\end{array}$ & \\
\hline $\begin{array}{l}\text { IPCC National } \\
\text { Accounting }\end{array}$ & $v$ & & & & & $v$ \\
\hline LEAP(ICLEI,2009) & & $v$ & $\begin{array}{l}\mathrm{V}(\text { required for aviation and } \\
\text { water transport and energy } \\
\text { embodied in energy. Others } \\
\text { are not mentioned/detailed) }\end{array}$ & & & $v$ \\
\hline $\mathrm{BEI} / \mathrm{MEI}(\mathrm{COM}, 2010)$ & & $v$ & $\begin{array}{l}V(\text { required for waste. Others } \\
\text { are not mentioned/detailed) }\end{array}$ & & & $v$ \\
\hline $\begin{array}{l}\text { ISDGC(UNEP et } \\
\text { al,2010) }\end{array}$ & & $v$ & $\begin{array}{l}V(\text { required for waste, aviation } \\
\text { and water transport. Others } \\
\text { are optional) }\end{array}$ & & & $v$ \\
\hline $\begin{array}{l}\text { US Community } \\
\text { Protocol(UNEP } \\
\text { USA,2013) }\end{array}$ & & $v$ & $\begin{array}{l}V \text { (required for energy and } \\
\text { water/wastewater, and waste. } \\
\text { Others are recommended) }\end{array}$ & $\checkmark$ (optional. Researcl & summarized.) & $v$ \\
\hline PAS2070 (BSI,2013) & & $v$ & $v($ DPSC method) & $\begin{array}{l}V \text { (CB method, optio } \\
\text { summarized.) }\end{array}$ & Research is & $v$ \\
\hline GPC (C40 et al.,2014) & & $V$ (GPC Basic) & V (GPC Basic+) & $\checkmark$ (mentioned, but $\mathrm{nc}$ & etailed) & $v$ \\
\hline
\end{tabular}


631 Each of the carbon accounting methods analysed in this article was designed for its own purpose and each has advantages and disadvantages when it comes to carbon mitigation policy.

\subsection{Advantages and disadvantages of the three methods for policy implication}

635

Pure-geographic PB method aligns well with the emerging effort to measure the carbon emissions of activities listed in the IPCC guidebook for countries. The city-scale carbon emission inventories can be added up geographically without double counting, which enables cities to easily implement national scale mitigation policies. It is also the easiest-to-conduct and it is the most widely adopted method for global cities with databases providing spatial solution data and bottom-up processed-based carbon emissions inventories (see details in SI).

642

However, the disadvantage of the pure-geographic PB is that it focuses exclusively on source-based activities within the city boundary, while many of these activities also consume the goods and services from outside of the city which cannot be targeted, rendering it ineffective and incomplete when it comes to mitigation policies. To illustrate, city-scale mitigation actions usually focus on electricity reduction for homes, businesses and industry within city boundaries but the power plants are often located outside the city boundary and so are not considered since the pure-geographic production-based method does not include emissions for electricity imported from outside its boundaries.

650

The CIF method is well-suited to inform urban infrastructure planning towards low-carbon development with assessment of co-benefits of adaption and health risk reduction. The approach focuses on seven infrastructure sectors that globally contribute about $90 \%$ of carbon emissions,(129) covering

654 the emissions that come from outside the city boundary in its low-carbon transition planning, e.g., transition to electrical vehicles. The community-wide infrastructure and food supply allows several 
aligns well with the GPC Basic+ and retains reporting on infrastructure use-activities. It promotes useefficiency metrics, a deprivation metric for each infrastructure sector and LCA-based footprint for each sector, which can be compared across cities and nations. The community-wide focus also allows circular economy strategies across producers and consumers in cities to be evaluated from an urban planning perspective.

The drawback of the CIF includes the incomplete or incomparable accounting of scope 3 for different cities because it leaves out "non-key" sectors on purpose. Hence, there is not yet an easy communitywide normalized metric, e.g. scope $1+2+3$ per capita or per GDP to rank cities. Emerging approaches to assess the liveability of the whole communities may provide a suitable normalizing metric based on real-time data instead of historical statistics.(130) By contrast, the CIF approach promotes infrastructure-focused accounting to support city-wide urban planning using historical statistics. Additionally, we also recommend not to add up scope 2 and 3 emissions from CIF for multiple cities to avoid double counting.

The CB method evaluates the transboundary lifecycle emissions of all goods and services linked to household consumption, government consumption and business capital expenditure. This consumptionbased CF can be normalized by population to provide a per capital number that can be compared across cities since the $\mathrm{CB}$ method has allocated the emissions generated within the city boundary for producing exported goods and services.(64) It also allows multiple cities to sum up their emissions without double counting for studying the co-benefit effect of urban agglomeration.(11) The CB method also builds on an endogenous connection with macro-scale economic analysis as the IO table captures the economic transactions along domestic and international trade.(53) The other advantage of the CB method is that it is able to combine macro-scale environmental accounting with micro-scale household consumption behaviour, thus linking individual's demographic and social-economic factors with the sustainable consumption studies and relevant policy for low-carbon behavioural change.(131) 
One disadvantage of the $\mathrm{CB}$ method is that it lacks the direct impact or reward system on the change of production activities. For example, because emissions embodied in exports are allocated to users outside the city, it passes on the responsibility of enhancement of energy efficiency to downstream customers' consumption patterns i.e. customers could choose carbon efficient products ("green labelling scheme") to push forward the low-carbon technology transformation in upstream producers, even though the production emissions are an essential part of the city's scope 1 inventory and can easily be targeted by upstream producers for improvement. The CB method is also unable to build linkages with communities' metabolic processes, e.g. pollution and infrastructure risk and resilience are difficult to cover. In addition, one of the most challenging parts for the CB method is to compile input-output tables at a cityscale level whereas there are official tables for countries.

694

Overall, there is no one method that is able to factor every possible contingency when it comes to citylevel carbon accounting. A primary recommendation of our analysis is the need to clearly communicate with policy makers what the different methods measure and what their particular focus is. This will assist policy makers to choose the right method for the purpose they wish to achieve.

\subsection{Key to advance accounting models}

The three carbon accounting methods can still be improved from several perspectives. The puregeographic PB method is erroneously called the production-based approach in some of the literature and is drawn from the IPCC national accounting. The definition of production-based emissions still needs to be clarified rather than linking it to GDP. Territorial emissions calculated by the puregeographic PB method play a fundamental role in supporting the hybrid and CB methods. The bottomup activity data and emission factors decide the quality of the territorial emissions, and can be collected from various sources such as from statistics reported in city or corporate self-reports. The top-down estimation by downscaling national or subnational carbon accounts to the local scale by spatial and socioeconomic proxies needs to pay attention to the issue such as emission source mismatch. The bottom-up estimation is relatively accurate while the top-down estimation is less labour-intensive. 
These two combined will supplement each other and enhance the accuracy and availability of data for cities. $(132,133)$

For CIF, the development of process-based LCA databases at a local scale can enhance the accuracy of calculations, while the national carbon intensity generated through the EIO-LCA model should ensure consistency with local carbon intensity. The hybrid LCA is a compromise between process-based LCA and EIO-LCA models, which could be a solution to ensuring better quality results. $(69,134)$ The other methods amalgamating process-based LCA, IO and MFA such as the mixed-unit hybrid life cycle assessment are also certainly worth exploring at the city-level.(75) Cities can also take advantage of digital supply chains and record the information of trade through these.(135). This may transform the way in which statistics are used for recording material flows and conducting MFA.

Regionalisation of the input-output table is the key to advance city-scale CB accounting. An ideal approach for gaining city-scale input-output is through bottom-up economic data collection (i.e. survey methods) such as that practiced in four provincial cities (Beijing, Shanghai, Tianjin and Chongqing) in China. However, this is a time-consuming and labour-intensive task as tables of this nature are difficult to generate for time series presentation. A less onerous means of gaining the input-output is to downscale the existing national or subnational input-output table, or extend the previous city-scale input-output table by non-survey methods according to different proxies.(136) However the lack of information about intermediate transactions and the structure of the value chains is still hampering the development of this method, and the assessment of uncertainty is also a challenge.(137) Accuracy relies on the quality of proxies and the optimization process for balancing different constraints of proxies as well as many other factors. One of the indicators for uncertainty analysis is carbon intensity. A robust modelling should ensure the carbon intensity generated from the input-output tables is comparable to the carbon intensity obtained through the bottom-up collection, especially for the electricity sector.

Studies regarding urban metabolism have potential in facilitating mitigation and adaption at the cityscale level. The discovery of the similarity in both ecological and economic input-output systems opens 
the door for applying the ecological principals in an environmental extended input-output model such as the controlled carbon footprint.(73) A city's CBF metric informs the total amount of emissions embodied in final demand, but controlled carbon footprint explains how much these emissions are actually controlled by the region and identifies the unfounded sectors that is able to lead to a low-carbon technology transformation. $(70,71)$ Studies regarding metabolic processes of resource flows are also important for low-carbon city strategies since they are always connected with upstream carbon emissions in complex ways.(138)

\section{Concluding remarks}

The citation network analysis presented in this article identifies the three most influential accounting perspectives in the literature (figure 1). It indicates that the field of city-level carbon accounting was dominated by pure-geographic production-based and community infrastructure-based accounting but emerging models combined with economic system analysis from a consumption-based perspective are leading to a new trend.

While university-based researchers continue to develop new and innovative models and applications, protocol-based practitioners commonly use the concept of scope1-3 for accounting and reporting, however, they do not pay much attention to innovations reported in the academic literature. The purpose of this study has been to attempt to fill this gap by integrating models into the three accounting perspectives (table 2) and connecting the scope 1-3 with the emissions calculated by them (figure 2 and figure S1). Any innovative model and application for city-scale carbon accounting should also clarify their relationship with scope 1-3 in future research, which is an effective way to convert them into an industrial practice.

The latest accounting protocols include consumption-based accounting, but most cities still limit their accounting and reporting in pure-geographic production-based and community infrastructure-based accounting due to the unavailability of data and complexity in applying the consumption-based 
accounting models (figure 3 and figure 4). Assisting protocol practitioners to conduct carbon accounting and explore the potential in mitigation and adaption from every perspective should also be a priority for future research.

\section{Acknowledgement}

Yafei Wang acknowledges the Major Program of National Philosophy and Social Science Foundation of China (Grant NO.16ZDA051). Guangwu Chen, Lei Shi and Thomas Wiedmann acknowledge the UNSW-Tsinghua Collaborative Research Fund. This project is also funded by China Postdoctoral Science Foundation (Grant NO.2018M641250).

\section{References}

1. IPCC In Cities and Climate Change Science Conference, Edmonton, Canada, March 5-7, 2018, 2018; 2018.

2. IPCC Global Research and Action Agenda on Cities and Climate Change Science; 2018.

3. Grimm, N. B.; Faeth, S. H.; Golubiewski, N. E.; Redman, C. L.; Wu, J.; Bai, X.; Briggs, J. M., Global change and the ecology of cities. science 2008, 319, (5864), 756-760.

4. Janssens-Maenhout, G.; Pagliari, V.; Guizzardi, D.; Muntean, M., Global emission inventories in the Emission Database for Global Atmospheric Research (EDGAR)-Manual (I). Gridding: EDGAR emissions distribution on global gridmaps, Publications Office of the European Union, Luxembourg 2013.

5. Hertwich, E. G.; Peters, G. P., Carbon Footprint of Nations: A Global, Trade-Linked Analysis. Environmental Science \& Technology 2009, 43, (16), 6414-6420.

6. Liang, S.; Wang, Y.; Zhang, C.; Xu, M.; Yang, Z.; Liu, W.; Liu, H.; Chiu, A. S. F., Final productionbased emissions of regions in China. Economic Systems Research 2018, 30, (1), 18-36.

7. Barrett, J.; Peters, G.; Wiedmann, T.; Scott, K.; Lenzen, M.; Roelich, K.; Le Quéré, C., Consumption-based GHG emission accounting: a UK case study. Climate Policy 2013, 13, (4), 451470.

8. Lombardi, M.; Laiola, E.; Tricase, C.; Rana, R., Assessing the urban carbon footprint: An overview. Environmental Impact Assessment Review 2017, 66, 43-52.

9. Hu, Y.; Lin, J.; Cui, S.; Khanna, N. Z., Measuring Urban Carbon Footprint from Carbon Flows in the Global Supply Chain. Environmental Science \& Technology 2016, 50, (12), 6154-6163.

10. Lin, J.; Hu, Y.; Cui, S.; Kang, J.; Ramaswami, A., Tracking urban carbon footprints from production and consumption perspectives. Environmental Research Letters 2015, 10, (5), 054001. 11. Wiedmann, T. O.; Chen, G.; Barrett, J., The Concept of City Carbon Maps: A Case Study of Melbourne, Australia. Journal of Industrial Ecology 2016.

12. Wiedmann, T.; Wood, R.; Minx, J.; Lenzen, M.; Guan, D.; Harris, R., A Carbon Footprint Time Series of the UK - Results from a Multi-Region Input-Output Model. Economic Systems Research 2010, 22, (1), 19-42. 

greenhouse gas emission footprint for cities: Mathematical relationships and policy relevance. Energy Policy 2013. Benchmarks for Eight U.S. Cities. Environmental Science \& Technology 2010, 44, (6), 1902-1910. Infrastructure-Based Greenhouse Gas Accounting for Delhi, India. Journal of Industrial Ecology 2012, 16, (6), 814-828.

16. Lin, J.; Liu, Y.; Meng, F.; Cui, S.; Xu, L., Using hybrid method to evaluate carbon footprint of Xiamen City, China. Energy Policy 2013, 58, (0), 220-227.

17. Qi, C.; Wang, Q.; Ma, X.; Ye, L.; Yang, D.; Hong, J., Inventory, environmental impact, and economic burden of GHG emission at the city level: Case study of Jinan, China. Journal of Cleaner Production 2018, 192, 236-243.

18. ICLEI, International local government GHG emissions analysis protocol (IEAP). In International Council for Local Environmental Initiatives Bonn: 2009.

19. IPCC, IPCC Guidelines for National Greenhouse Gas Inventories. IGES: Japan, 2006.

20. WBCSD; WRI, The greenhouse gas protocol: a corporate accounting and reporting standard. WBCSD:World Business Council for Sustainable Development; WRI:World Resources Institute. World Resources Inst: 2001.

21. UNEP; UN-HABITAT; Bank, W., International Standard for Determining Greenhouse Gas Emissions for Cities. In 2010.

22. WRI; C40; ICLEI, Global Protocol for Community-Scale Greenhouse Gas Emission Inventories (GPC) - An Accounting and Reporting Standard for Cities. . In World Resources Institute, C40 Cities Climate Leadership Group and ICLEI Local Governments for Sustainability: 2014.

23. BSI, PAS 2070: Specification for the assessment of greenhouse gas emissions of a city. BSI: British Standard Institue British Standards institutuion 2013.

24. ICLEI.USA, U.S. Community Protocol for Accounting and Reporting of Greenhouse Gas Emissions. In 2013.

25. Andrade, J. C. S.; Dameno, A.; Pérez, J.; de Andrés Almeida, J. M.; Lumbreras, J., Implementing city-level carbon accounting: A comparison between Madrid and London. Journal of Cleaner Production 2018, 172, 795-804.

26. Kennedy, S.; Sgouridis, S., Rigorous classification and carbon accounting principles for low and Zero Carbon Cities. Energy Policy 2011, 39, (9), 5259-5268.

27. Ibrahim, N.; Sugar, L.; Hoornweg, D.; Kennedy, C., Greenhouse gas emissions from cities: comparison of international inventory frameworks. Local Environment 2012, 17, (2), 223-241. 28. Fry, J.; Lenzen, M.; Jin, Y.; Wakiyama, T.; Baynes, T.; Wiedmann, T.; Malik, A.; Chen, G.; Wang, Y.; Geschke, A.; Schandl, H., Assessing carbon footprints of cities under limited information. Journal of Cleaner Production 2018, 176, 1254-1270.

29. Chen, C., CiteSpace II: Detecting and visualizing emerging trends and transient patterns in scientific literature. Journal of the Association for Information Science and Technology 2006, 57, (3), 359-377.

30. Satterthwaite, D., Cities' contribution to global warming: notes on the allocation of greenhouse gas emissions. Environment and urbanization 2008, 20, (2), 539-549.

31. Kennedy, C.; Steinberger, J.; Gasson, B.; Hansen, Y.; Hillman, T.; Havránek, M.; Pataki, D.; Phdungsilp, A.; Ramaswami, A.; Mendez, G. V., Greenhouse Gas Emissions from Global Cities. Environmental Science and Technology 2009, 43, 7297-7302.

32. Kennedy, C.; Steinberger, J.; Gasson, B.; Hansen, Y.; Hillman, T.; Havránek, M.; Pataki, D.; Phdungsilp, A.; Ramaswami, A.; Mendez, G. V., Methodology for inventorying greenhouse gas emissions from global cities. Energy Policy 2010, 38, (9), 4828-4837.

33. Hoornweg, D.; Sugar, L.; Trejos Gómez, C. L., Cities and greenhouse gas emissions: moving forward. Environment and Urbanization 2011, 23, (1), 207-227. 
34. Baynes, T. M.; Wiedmann, T., General approaches for assessing urban environmental sustainability. General approaches for assessing urban environmental sustainability 2012, 4, (4), 458-464

35. Jones, C.; Kammen, D. M., Spatial distribution of US household carbon footprints reveals suburbanization undermines greenhouse gas benefits of urban population density. Environmental Science \& Technology 2014, 48, (2), 895-902.

36. Larsen, H. N.; Hertwich, E. G., The case for consumption-based accounting of greenhouse gas emissions to promote local climate action. Environmental Science \& Policy 2009, 12, (7), 791-798. 37. Lenzen, M.; Peters, G. M., How City Dwellers Affect Their Resource Hinterland - A Spatial Impact Study of Australian Households. Journal of Industrial Ecology 2010, 14, (1), 73-90.

38. Minx, J.; Baiocchi, G.; Wiedmann, T.; Barrett, J.; Creutzig, F.; Feng, K.; Förster, M.; Pichler, P.P.; Weisz, H.; Hubacek, K., Carbon footprints of cities and other human settlements in the UK. Environ Res Lett 2013, 8, (3), 035039.

39. Glaeser, E. L.; Kahn, M., The greenness of cities: Carbon dioxide emissions and urban development. Journal of Urban Economics 2010, 67, (3), 404-418.

40. Sovacool, B. K.; Brown, M. A., Twelve metropolitan carbon footprints: A preliminary comparative global assessment. Energy Policy 2010, 38, (9), 4856-4869.

41. Ramaswami, A.; Hillman, T.; Janson, B.; Reiner, M.; Thomas, G., A demand-centered, hybrid life-cycle methodology for city-scale greenhouse gas inventories. Environmental Science \& Technology 2008, 42, (17), 6455-6461.

42. Dodman, D., Blaming cities for climate change? An analysis of urban greenhouse gas emissions inventories. Environment and Urbanization 2009, 21, (1), 185-201.

43. Ramaswami, A.; Chavez, A.; Ewing-Thiel, J.; Reeve, K. E., Two Approaches to Greenhouse Gas Emissions Foot-Printing at the City Scale. Environmental Science \& Technology 2011, 45, (10), 42054206.

44. Weber, C. L.; Matthews, H. S., Quantifying the global and distributional aspects of American household carbon footprint. Ecological Economics 2008, 66, (2), 379-391.

45. Dhakal, S., Urban energy use and carbon emissions from cities in China and policy implications. Energy Policy 2009, 37, (11), 4208-4219.

46. Liu, Z.; Geng, Y.; Lindner, S.; Zhao, H.; Fujita, T.; Guan, D., Embodied energy use in China's industrial sectors. Energy Policy 2012, 49, (0), 751-758.

47. Feng, K.; Hubacek, K.; Sun, L.; Liu, Z., Consumption-based CO 2 accounting of China's megacities: the case of Beijing, Tianjin, Shanghai and Chongqing. Ecological Indicators 2014, 47, 2631.

48. Mi, Z.; Zhang, Y.; Guan, D.; Shan, Y.; Liu, Z.; Cong, R.; Yuan, X.-C.; Wei, Y.-M., Consumptionbased emission accounting for Chinese cities. Applied Energy 2016.

49. Jones, C. M.; Kammen, D. M., Quantifying Carbon Footprint Reduction Opportunities for U.S. Households and Communities. Environmental Science \& Technology 2011, 45, (9), 4088-4095.

50. Jones, C. M.; Wheeler, S. M.; Kammen, D. M., Carbon footprint planning: Quantifying local and state mitigation opportunities for 700 California Cities. 2018.

51. Shan, Y.; Guan, D.; Liu, J.; Mi, Z.; Liu, Z.; Liu, J.; Schroeder, H.; Cai, B.; Chen, Y.; Shao, S.; Zhang, Q., Methodology and applications of city level $\mathrm{CO} 2$ emission accounts in China. Journal of Cleaner Production 2017, 161, 1215-1225.

52. Shan, Y.; Guan, D.; Hubacek, K.; Zheng, B.; Davis, S. J.; Jia, L.; Liu, J.; Liu, Z.; Fromer, N.; Mi, Z., City-level climate change mitigation in China. Science Advances 2018, 4, (6), eaaq0390.

53. Chen, G.; Hadjikakou, M.; Wiedmann, T., Urban carbon transformations: unravelling spatial and inter-sectoral linkages for key city industries based on multi-region input-output analysis. Journal of Cleaner Production 2017, 163, 224-240.

54. Su, B.; Ang, B. W.; Li, Y., Input-output and structural decomposition analysis of Singapore's carbon emissions. Energy Policy 2017, 105, 484-492. 
55. Zhang, Y.; Wu, Q.; Fath, B. D., Review of spatial analysis of urban carbon metabolism. Ecological Modelling 2018, 371, 18-24.

56. Peters, G. P., From production-based to consumption-based national emission inventories. Ecological Economics 2008, 65, (1), 13-23.

57. Ramaswami, A.; Chavez, A.; Chertow, M., Carbon Footprinting of Cities and Implications for Analysis of Urban Material and Energy Flows. Journal of Industrial Ecology 2012, 16, (6), 783-785. 58. Cai, B.; Zhang, L., Urban $\mathrm{CO} 2$ emissions in China: Spatial boundary and performance comparison. Energy Policy 2014, 66, 557-567.

59. Wang, J.; Cai, B.; Zhang, L.; Cao, D.; Liu, L.; Zhou, Y.; Zhang, Z.; Xue, W., High Resolution Carbon Dioxide Emission Gridded Data for China Derived from Point Sources. Environmental Science \& Technology 2014, 48, (12), 7085-7093.

60. Wang, M.; Cai, B., A two-level comparison of $\mathrm{CO} 2$ emission data in China: Evidence from three gridded data sources. Journal of Cleaner Production 2017, 148, 194-201.

61. Cai, B., Study on key issues of city carbon emission inventory. Chemical Industry Press: Beijing, 2014.

62. Ling, S.; Dabo, G.; Ning, Z.; Yuli, S.; Chen, G. Q., Carbon emissions from fossil fuel consumption of Beijing in 2012. Environmental Research Letters 2016, 11, (11), 114028.

63. Malik, A.; McBain, D.; Wiedmann, T. O.; Lenzen, M.; Murray, J., Advancements in Input Output Models and Indicators for Consumption - Based Accounting. Journal of Industrial Ecology 2018.

64. Chen, G.; Wiedmann, T.; Wang, Y.; Hadjikakou, M., Transnational city carbon footprint networks-Exploring carbon links between Australian and Chinese cities. Applied Energy 2016. 65. Heinonen, J.; Jalas, M.; Juntunen, J. K.; Ala-Mantila, S.; Junnila, S., Situated lifestyles: I. How lifestyles change along with the level of urbanization and what the greenhouse gas implications are-a study of Finland. Environmental Research Letters 2013, 8, (2), 025003.

66. Chen, G.; Wiedmann, T.; Hadjikakou, M.; Rowley, H., City Carbon Footprint Networks. Energies 2016, 9, (8), 602.

67. Minx, J. C.; Wiedmann, T.; Wood, R.; Peters, G. P.; Lenzen, M.; Owen, A.; Scott, K.; Barrett, J.; Hubacek, K.; Baiocchi, G., Input-output analysis and carbon footprinting: an overview of applications. Economic Systems Research 2009, 21, (3), 187-216.

68. Zheng, B.; Zhang, Q.; Davis, S. J.; Ciais, P.; Hong, C.; Li, M.; Liu, F.; Tong, D.; Li, H.; He, K., Infrastructure Shapes Differences in the Carbon Intensities of Chinese Cities. Environmental Science \& Technology 2018, 52, (10), 6032-6041.

69. Heinonen, J.; Junnila, S., Implications of urban structure on carbon consumption in metropolitan areas. Environmental Research Letters 2011, 6, (1), 014018.

70. Chen, S.; Chen, B. J. E. s.; technology, Tracking inter-regional carbon flows: a hybrid network model. 2016, 50, (9), 4731-4741.

71. Chen, S.; Zhu, F., Unveiling key drivers of urban embodied and controlled carbon footprints. Applied Energy 2019, 235, 835-845.

72. Fath, B. D., Distributed control in ecological networks. Ecological Modelling 2004, 179, (2), 235-245.

73. Hannon, B., The structure of ecosystems. Journal of Theoretical Biology 1973, 41, (3), 535546.

74. Froemelt, A.; Mauchle, M.; Steubing, B.; Hellweg, S., Greenhouse Gas Emissions Quantification and Reduction Efforts in a Rural Municipality. Journal of Industrial Ecology 2018, 22, (1), 92-105.

75. Teh, S. H.; Wiedmann, T.; Moore, S., Mixed-unit hybrid life cycle assessment applied to the recycling of construction materials. Journal of Economic Structures 2018, 7, (1), 13.

76. Meng, L.; Graus, W.; Worrell, E.; Huang, B., Estimating CO2 (carbon dioxide) emissions at urban scales by DMSP/OLS (Defense Meteorological Satellite Program's Operational Linescan 
System) nighttime light imagery: Methodological challenges and a case study for China. Energy 2014, $961 \quad 71,468-478$.

962 77. Su, Y.; Chen, X.; Li, Y.; Liao, J.; Ye, Y.; Zhang, H.; Huang, N.; Kuang, Y., China's 19-year citylevel carbon emissions of energy consumptions, driving forces and regionalized mitigation guidelines. Renewable and Sustainable Energy Reviews 2014, 35, 231-243.

78. Wang, S.; Liu, X., China's city-level energy-related CO2 emissions: Spatiotemporal patterns and driving forces. Applied Energy 2017, 200, 204-214.

79. Liu, X.; Ou, J.; Wang, S.; Li, X.; Yan, Y.; Jiao, L.; Liu, Y., Estimating spatiotemporal variations of city-level energy-related $\mathrm{CO} 2$ emissions: An improved disaggregating model based on vegetation adjusted nighttime light data. Journal of Cleaner Production 2018, 177, 101-114.

80. Daniel, M.; Keiichiro, K.; Magnus, J.; Richard, W.; Johannes, T.; Karen, S., Carbon footprints of 13,000 cities. Environmental Research Letters 2018.

81. Marcotullio, P. J.; Sarzynski, A.; Albrecht, J.; Schulz, N., A Top-Down Regional Assessment of Urban Greenhouse Gas Emissions in Europe. AMBIO 2014, 43, (7), 957-968.

82. Asefi - Najafabady, S.; Rayner, P.; Gurney, K.; McRobert, A.; Song, Y.; Coltin, K.; Huang, J.; Elvidge, C.; Baugh, K., A multiyear, global gridded fossil fuel $\mathrm{CO} 2$ emission data product: Evaluation and analysis of results. Journal of Geophysical Research: Atmospheres 2014, 119, (17).

83. Xi, F.; Geng, Y.; Chen, X.; Zhang, Y.; Wang, X.; Xue, B.; Dong, H.; Liu, Z.; Ren, W.; Fujita, T.; Zhu, Q., Contributing to local policy making on GHG emission reduction through inventorying and attribution: A case study of Shenyang, China. Energy Policy 2011, 39, (10), 5999-6010.

84. Wang, H.; Zhang, R.; Liu, M.; Bi, J., The carbon emissions of Chinese cities. Atmospheric Chemistry and Physics 2012, 12, (14), 6197-6206.

85. Liu, Z.; Liang, S.; Geng, Y.; Xue, B.; Xi, F.; Pan, Y.; Zhang, T.; Fujita, T., Features, trajectories and driving forces for energy-related GHG emissions from Chinese mega cites: the case of Beijing, Tianjin, Shanghai and Chongqing. Energy 2012, 37, (1), 245-254.

86. Sugar, L.; Kennedy, C.; Leman, E., Greenhouse gas emissions from Chinese cities. Journal of Industrial Ecology 2012, 16, (4), 552-563.

87. Zhang, J.; Zhang, Y.; Yang, Z.; Fath, B. D.; Li, S., Estimation of energy-related carbon emissions in Beijing and factor decomposition analysis. Ecological Modelling 2013, 252, 258-265.

88. Ramachandra, T. V.; Aithal, B. H.; Sreejith, K., GHG footprint of major cities in India.

Renewable and Sustainable Energy Reviews 2015, 44, 473-495.

89. Chen, Q.; Cai, B.; Dhakal, S.; Pei, S.; Liu, C.; Shi, X.; Hu, F., CO2 emission data for Chinese cities. Resources, Conservation and Recycling 2017, 126, 198-208.

90. Markolf, S. A.; Matthews, H. S.; Azevedo, I. L.; Hendrickson, C., An integrated approach for estimating greenhouse gas emissions from 100 US metropolitan areas. Environmental Research Letters 2017, 12, (2), 024003.

91. Cai, B.; Guo, H.; Cao, L.; Guan, D.; Bai, H., Local strategies for China's carbon mitigation: An investigation of Chinese city-level CO2 emissions. Journal of Cleaner Production 2018, 178, 890-902. 92. Cai, B.; Li, W.; Dhakal, S.; Wang, J., Source data supported high resolution carbon emissions inventory for urban areas of the Beijing-Tianjin-Hebei region: Spatial patterns, decomposition and policy implications. Journal of Environmental Management 2018, 206, 786-799.

93. Xu, X.; Huo, H.; Liu, J.; Shan, Y.; Li, Y.; Zheng, H.; Guan, D.; Ouyang, Z., Patterns of CO2 emissions in 18 central Chinese cities from 2000 to 2014. Journal of Cleaner Production 2018, 172, 529-540.

94. Shan, Y.; Zheng, H.; Guan, D.; Li, C.; Mi, Z.; Meng, J.; Schroeder, H.; Ma, J.; Ma, Z., Energy consumption and CO2 emissions in Tibet and its cities in 2014. Earth's Future 2018.

95. Lombardi, M.; Laiola, E.; Tricase, C.; Rana, R., Toward urban environmental sustainability: The carbon footprint of Foggia's municipality. Journal of Cleaner Production 2018, 186, 534-543. 96. Cai, B.; Lu, J.; Wang, J.; Dong, H.; Liu, X.; Chen, Y.; Chen, Z.; Cong, J.; Cui, Z.; Dai, C., A benchmark city-level carbon dioxide emission inventory for China in 2005. Applied Energy 2019, 233, 659-673. 
97. Guo, S.; Shao, L.; Chen, H.; Li, Z.; Liu, J. B.; Xu, F. X.; Li, J. S.; Han, M. Y.; Meng, J.; Chen, Z.-M.; $\mathrm{Li}, \mathrm{S}$. C., Inventory and input-output analysis of $\mathrm{CO} 2$ emissions by fossil fuel consumption in Beijing 2007. Ecological Informatics 2012, 12, 93-100.

98. Wang, Y.; Zhao, H.; Li, L.; Liu, Z.; Liang, S., Carbon dioxide emission drivers for a typical metropolis using input-output structural decomposition analysis. Energy Policy 2013, 58, (0), 312318.

99. Chen, G. Q.; Guo, S.; Shao, L.; Li, J. S.; Chen, Z.-M., Three-scale input-output modeling for urban economy: Carbon emission by Beijing 2007. Communications in Nonlinear Science and Numerical Simulation 2013, 18, (9), 2493-2506.

100. Hermannsson, K.; McIntyre, S. G., Local consumption and territorial based accounting for $\mathrm{CO} 2$ emissions. Ecol Econ 2014, 104, (0), 1-11.

101. Yao, L.; Liu, J.; Wang, R.; Yin, K., Carbon footprint accounting of regional household consumption in China through multi-regional input-output model. Huanjing Kexue Xuebao/Acta Scientiae Circumstantiae 2013, 33, (7), 2050-2058.

102. Zhang, B.; Qiao, H.; Chen, B., Embodied energy uses by China's four municipalities: a study based on multi-regional input-output model. Ecological Modelling 2015, 318, 138-149.

103. Lin, J.; Hu, Y.; Zhao, X.; Shi, L.; Kang, J., Developing a city-centric global multiregional inputoutput model (CCG-MRIO) to evaluate urban carbon footprints. Energy Policy 2017, 108, 460-466.

104. Li, Y. L.; Chen, B.; Han, M. Y.; Dunford, M.; Liu, W.; Li, Z., Tracking carbon transfers embodied in Chinese municipalities' domestic and foreign trade. Journal of Cleaner Production 2018.

105. Pichler, P.-P.; Zwickel, T.; Chavez, A.; Kretschmer, T.; Seddon, J.; Weisz, H., Reducing Urban Greenhouse Gas Footprints. Scientific reports 2017, 7, (1), 14659.

106. Athanassiadis, A.; Christis, M.; Bouillard, P.; Vercalsteren, A.; Crawford, R. H.; Khan, A. Z., Comparing a territorial-based and a consumption-based approach to assess the local and global environmental performance of cities. Journal of Cleaner Production 2018, 173, 112-123.

107. Chen, G.; Hadjikakou, M.; Wiedmann, T.; Shi, L., Global warming impact of suburbanization: The case of Sydney. Journal of Cleaner Production 2018, 172, 287-301.

108. Larsen, H. N.; Hertwich, E. G., Identifying important characteristics of municipal carbon footprints. Ecological Economics 2010, 70, (1), 60-66.

109. Larsen, H. N.; Hertwich, E. G., Implementing Carbon-Footprint-Based Calculation Tools in Municipal Greenhouse Gas Inventories. Journal of Industrial Ecology 2010, 14, (6), 965-977.

110. Larsen, H. N.; Hertwich, E. G., Analyzing the carbon footprint from public services provided by counties. Journal of Cleaner Production 2011, 19, (17-18), 1975-1981.

111. Petsch, S.; Guhathakurta, S.; Heischbourg, L.; Müller, K.; Hagen, H., Modeling, Monitoring, and Visualizing Carbon Footprints at the Urban Neighborhood Scale. Journal of Urban Technology 2011, 18, (4), 81-96.

112. Ala-Mantila, S.; Heinonen, J.; Junnila, S., Greenhouse Gas Implications of Urban Sprawl in the Helsinki Metropolitan Area. Sustainability 2013, 5, (10).

113. Ala-Mantila, S.; Heinonen, J.; Junnila, S., Relationship between urbanization, direct and indirect greenhouse gas emissions, and expenditures: A multivariate analysis. Ecological Economics 2014, 104, 129-139.

114. Dias, A. C.; Lemos, D.; Gabarrell, X.; Arroja, L., Environmentally extended input-output analysis on a city scale - application to Aveiro (Portugal). Journal of Cleaner Production 2014, 75, (0), 118-129.

115. Chen, S.; Chen, B., Changing Urban Carbon Metabolism over Time: Historical Trajectory and Future Pathway. Environmental Science \& Technology 2017, 51, (13), 7560-7571.

116. Chen, S.; Xu, B.; Chen, B., Unfolding the interplay between carbon flows and socioeconomic development in a city: What can network analysis offer? Applied Energy 2018, 211, 403-412.

117. Chen, S.; Liu, Z.; Chen, B.; Zhu, F.; Fath, B. D.; Liang, S.; Su, M.; Yang, J. J. E. s. F., Dynamic carbon emission linkages across boundaries. 2019, Earth's Future 7, 197-209. 
118. Chavez, A.; Ramaswami, A., Progress toward low carbon cities: approaches for transboundary GHG emissions' footprinting. Carbon Management 2011, 2, (4), 471-482. 119. Tong, K.; Fang, A.; Boyer, D.; Hu, Y.; Cui, S.; Shi, L.; Kalmykova, Y.; Ramaswami, A., Greenhouse gas emissions from key infrastructure sectors in larger and smaller Chinese cities: method development and benchmarking. Carbon Management 2016, 7, (1-2), 27-39.

120. ICLEI ABOUT ICLEI. http://www.iclei.org/about/who-is-iclei/faq.html

121. Staden, M. v.; Klas, C., 3.3 ICLEI's Support for Local Climate Action: A Selection of Tools, Local Governments and Climate Change. Springer: New York, 2010.

122. C40 ABOUT C40. http://www.c40.org/about

123. Torres, P. B.; Doubrava, R., 3.2 The Covenant of Mayors: Cities Leading the Fight Against the Climate Change,,Local Governments and Climate Change. Springer: New York2010.

124. GCoM, History of the Global Covenant. GCoM:Global Covenant of Mayors for Climate \& Energy. In 2018.

125. CARB; CCAR; ICLEl; Registry, T. C., Local Government Operations Protocol For the quantification and reporting of greenhouse gas emissions inventories. CARB:California Air Resources Board; CCAR:California Climate Action Registry 2010.

126. COM, Baseline Emissions Inventory/Monitoring Emissions Inventory methodology. COM:Covenant of Mayors. In 2010.

127. ICLEI, U.S. Community Protocol for Accounting and Reporting of Greenhouse Gas Emissions. ICLEI: Local Governments for Sustainability. 2013.

128. BSI, Application of PAS 2070 -London, United Kingdom:An assessment of greenhouse gas emissions of a city. BSI: British Standard Institute In 2014.

129. Ramaswami, A.; Russell, A. G.; Culligan, P. J.; Sharma, K. R.; Kumar, E. J. S., Meta-principles for developing smart, sustainable, and healthy cities. 2016, 352, (6288), 940-943.

130. Marsal-Llacuna, M.-L.; Colomer-Llinàs, J.; Meléndez-Frigola, J., Lessons in urban monitoring taken from sustainable and livable cities to better address the Smart Cities initiative. Technological Forecasting and Social Change 2015, 90, 611-622.

131. Druckman, A.; Jackson, T., The carbon footprint of UK households 1990-2004: A socioeconomically disaggregated, quasi-multi-regional input-output model. Ecological Economics 2009, 68, (7), 2066-2077.

132. Shan, Y.; Guan, D.; Hubacek, K.; Zheng, B.; Davis, S. J.; Jia, L.; Liu, J.; Liu, Z.; Fromer, N.; Mi, Z.; Meng, J.; Deng, X.; Li, Y.; Schroeder, H.; Weisz, H.; Schellnhuber, H. J., City-level climate change mitigation in China. Science Advances 2018, 4, eaaq0390.

133. Shan, Y.; Liu, J.; Liu, Z.; Shao, S.; Guan, D., An emissions-socioeconomic inventory of Chinese cities. Scientific Data 2019, 6, 190027.

134. Baynes, T. M.; Crawford, R. H.; Schinabeck, J.; Bontinck, P.-A.; Stephan, A.; Wiedmann, T.; Lenzen, M.; Kenway, S.; Yu, M.; Teh, S. H.; Lane, J.; Geschke, A.; Fry, J.; Chen, G., The Australian industrial ecology virtual laboratory and multi-scale assessment of buildings and construction. Energy and Buildings 2018, 164, 14-20.

135. Korpela, K.; Hallikas, J.; Dahlberg, T. In Digital supply chain transformation toward blockchain integration, proceedings of the 50th Hawaii international conference on system sciences, 2017; 2017.

136. Wang, Y.; Geschke, A.; Lenzen, M., Constructing a Time Series of Nested Multiregion InputOutput Tables. International Regional Science Review 2015, 0160017615603596.

137. Sun, Z.; Tukker, A.; Behrens, P., Going Global to Local: Connecting Top-Down Accounting and Local Impacts, A Methodological Review of Spatially Explicit Input-Output Approaches.

Environmental Science \& Technology 2019, 53, (3), 1048-1062.

138. Kennedy, C. A., Chapter nine cities in a low-carbon world. Cities in the 21st Century 2016, 109. 